\title{
Free Radical Scavengers from the Mexican Herbal Tea "Poleo" (Hedeoma drummondii)
}

Ezequiel Viveros-Valdez ${ }^{\mathrm{a}, \mathrm{b}}$, Catalina Rivas-Morales ${ }^{\mathrm{a}}$, Pilar Carranza-Rosales ${ }^{\mathrm{b}}$, Sandra Mendoza ${ }^{\mathrm{c}}$, and Guillermo Schmeda-Hirschmann ${ }^{\mathrm{d}, *}$

a Departamento de Química, Facultad de Ciencias Biológicas, Universidad Autónoma de Nuevo León, San Nicolás de los Garza, Mexico

b División de Biología Celular y Molecular, Centro de Investigación Biomédica del Noreste, Monterrey, Mexico

c Facultad de Química, Universidad Autónoma de Querétaro, Querétaro, Mexico

d Laboratorio de Química de Productos Naturales, Instituto de Química de Recursos Naturales, Universidad de Talca, Talca, Chile. E-mail: schmeda@utalca.cl

* Author for correspondence and reprint requests

Z. Naturforsch. 63c, 341-346 (2008); received October 11/December 3, 2007

The aerial parts of the Lamiaceae Hedeoma drummondii (Benth.) are used in Mexico to prepare a herbal tea and by North American Amerindians as a spice. The methanolic extract of the aerial parts exhibited a strong antioxidant effect measured by the scavenging of the free diphenyl picrylhydrazyl (DPPH) radical. Assay-guided fractionation of the crude methanolic extract allowed the identification of three major active constituents, chlorogenic, caffeic and rosmarinic acid, as well as sideritoflavone derivatives and simple phenolics. The TEAC, FRAP, total phenolic and flavonoid content were determined. The high content of caffeic acid and rosmarinic acid relates to the antioxidant activity of $H$. drummondii.

Key words: Hedeoma drummondii, Lamiaceae, Free Radical Scavengers

\section{Introduction}

Several secondary plant metabolites are thought to be beneficial for human health and disease prevention. Antioxidant compounds are a relevant group of products with nutraceutical properties that can be found in vegetables, fruits and herbal teas (Ness and Powles, 1997; Steinmetz and Potter, 1991; Heinonen et al., 1998; Record et al., 2001; Wang et al., 1996). Plant phenolics provide protection against the harmful effects of oxidative stress, which is related to the risk of coronary heart disease, cardiovascular disease, atherosclerosis, inflammation (Youdim et al., 2002; Andersen et al., 2006; Luyten et al., 2005), certain types of cancer (Neto, 2007) and other neurodegenerative diseases (Spiteller, 2006).

The Lamiaceae is one of the plant families most intensively studied and tested for its antioxidant activity. In Mexico, several species belonging to this plant family have been used since pre-Hispanic times as spices, teas and medicinal plants. After Spanish conquest, several Lamiaceae from the Mediterranean basin were introduced and are now extensively used for cooking as well as for medicinal purposes, like "albahaca" (Ocimum basilicum L.), "tomillo" (Thymus vulgaris L.) and "menta" (Mentha piperita L.). The blend of old Amerindian tradition and European aromatic plants gives Mexican cuisine a distinct flavour and taste. While some genera belonging to the Lamiaceae have been extensively investigated both for secondary metabolites and biological activity, such as Salvia, Melissa, Mentha, Thymus, Lavandula, Rosmarinus and Origanum (Zgórka and Głowniak, 2001; Dorman et al., 2003), little is known on the North American species from the genus Hedeoma. Hedeoma drummondii has been used as a spice in soups, and as a tea to relieve cold and cough in the north of Mexico and USA (Gilmore, 1913; Vestal, 1952; Rogers, 1980; González, 1998; Estrada et al., 2007).

Taking into account that plants belonging to the Lamiaceae family are good sources of antioxidants, including flavonoids and phenolic acids (Grayer et al., 2003; Proestos et al., 2006), the aim of this study was to assess the antioxidant activity of the Mexican aromatic plant Hedeoma drummondii and to identify the main compounds responsible for this activity. 


\section{Materials and Methods}

\section{General}

The NMR spectra of the isolated compounds were recorded on a Bruker Avance 400 NMR spectrometer operating at $400 \mathrm{MHz}$ for ${ }^{1} \mathrm{H}$ and 100 $\mathrm{MHz}$ for ${ }^{13} \mathrm{C}$ NMR. Samples were dissolved in deuterated methanol. Mass spectra were obtained on a MAT 95XP Thermo Finnigan spectrometer using perfluoro terbutylamine, FC43, as a reference. A Lambda 40 Perkin Elmer UV/Visible instrument and an ELX 800 microplate reader BioTeK equipment were used for colorimetric and spectrophotometric determinations. GC-MS was carried out using a Perkin-Elmer AutoSystem GC equipment and a Quadrex 007.5MS column $(30 \mathrm{~m} \times 0.25 \mathrm{~mm}$, film thickness $0.25 \mu \mathrm{m})$ : carrier gas, helium; split flow, $50 \mathrm{ml} / \mathrm{min}$; initial setpoint, 10 PSIG; oven program: initial temperature $40^{\circ} \mathrm{C}$, hold for $1.0 \mathrm{~min}$, ramp $5.0^{\circ} \mathrm{C} / \mathrm{min}$ to $260^{\circ} \mathrm{C}$, hold for $0.00 \mathrm{~min}$; total run time $45.00 \mathrm{~min}$. MS: PE Turbomass full scan 40 to 400 mass units, EI+ (centroid). HPLC analysis was performed using a HPLC-DAD Merck-Hitachi (LaChrom, Tokyo, Japan) equipment consisting of an L-7100 pump, an L-7455 UV diode array detector and a D-7000 chromato-integrator. For analytical purposes, a C18-RP column $(250 \times 4.6 \mathrm{~mm}$ i.d., $5 \mu \mathrm{m})$ (Phenomenex, Torrence, CA) was used. For the semipreparative isolation, a Merck Lichrospher column $(250 \times 25 \mathrm{~mm}$ i.d., $7 \mu \mathrm{m})$ was used. Gel permeation was performed on Sephadex LH-20 (Pharmacia). Pre-coated thin layer chromatography plates were from Merck (Darmstadt, Germany), 1,1-diphenyl-2-picrylhydrazyl (DPPH) radical, diphenylborinic acid ethanolamine ester, gallic acid, (+)-catechin and the other reagents were purchased from Sigma-Aldrich Chemical Co. (St. Louis, MO, USA). The solvents used for chromatography were HPLC grade and the other chemicals were analytical grade.

\section{Plant material and extraction}

The aerial parts of Hedeoma drummondii (Benth.) (Lamiaceae) were collected in Allende, Nuevo León state, Mexico, in May/June 2005. The plant was identified by Dr. Marcela González Alvarez and a voucher specimen was deposited in the ethnobotanical collection of the herbarium FCB-UANL, San Nicolás de los Garza, NL, Mexico (voucher specimen number 024244).
The aerial parts of the plant were dried at room temperature and $1 \mathrm{~kg}$ of the dry, powdered material was extracted with $\mathrm{MeOH}$ by maceration $(3 \times 24 \mathrm{~h})$. The plant-solvent ratio was $1: 5 \mathrm{w} / \mathrm{v}$. After filtration and concentration under reduced pressure, $95 \mathrm{~g}$ of a dark-green extract were obtained (w/w yield $9.5 \%)$.

\section{Determination of total phenolic and flavonoid content}

The total phenolic content was determined using the Folin-Ciocalteu reagent as described by Singleton and Rossi (1965) with some modifications. Samples $(100 \mu \mathrm{l})$ were placed in test tubes, $250 \mu \mathrm{l}$ of Folin-Ciocalteu ( $1 \mathrm{~N})$ reagent, $1250 \mu \mathrm{l}$ of sodium carbonate $(20 \%)$ and $400 \mu$ l of distilled water were added. The mixture was incubated for $2 \mathrm{~h}$ and the change in absorbance was measured at $760 \mathrm{~nm}$. Gallic acid was used as a standard. The total phenolic content was expressed as mg gallic acid equivalent (eq)/g dry extract. Results are presented as means $\pm \mathrm{SD}$. Each measurement was performed at least in triplicate.

The flavonoid content was determined by the aluminum chloride colorimetric method according to Chang et al. (2002). (+)-Catechin was used as a reference for the calibration curve. The absorbance of the reaction mixture was measured at $415 \mathrm{~nm}$. Results are expressed as mg (+)-catechin equivalent (eq)/g extract. Data are reported as means \pm SD for at least three replicates.

\section{ABTS assay}

The Trolox equivalent antioxidant capacity (TEAC) of the extract was determined by the ABTS [2,2'-azinobis(3-ethylbenzothiazoline-6-sulfonic acid)] radical cation discoloration assay ( $\mathrm{Re}$ et al., 1999) and the values are reported as $\mu \mathrm{M}$ Trolox. The method is based on the consumption of the preformed $\mathrm{ABTS}^{\bullet+}$ in the presence of potassium persulfate followed at the maximum absorption of $734 \mathrm{~nm}$. Added antioxidants reduce ABTS $^{\bullet+}$ to ABTS. The assay was performed in 96well microplates, the absorbance of $\mathrm{ABTS}^{\bullet+}$ was adjusted to $0.70 \pm 0.02$. The decrease of the absorption was measured after $6 \mathrm{~min}$. The results are presented as means $\pm \mathrm{SD}$. Each measurement was performed at least in triplicate. 


\section{FRAP assay}

The ferric reducing antioxidant power (FRAP) assay uses antioxidants as reductants in a redoxlinked colorimetric method. The antioxidant activity was measured by the sample ability to reduce the $\mathrm{Fe}^{3+} /$ ferricyanide complex by forming ferrous products in a 96-well microplate reader. Absorbance was measured at $595 \mathrm{~nm}$ exactly $8 \mathrm{~min}$ after mixing the FRAP solution and the sample. $25 \mu \mathrm{l}$ of $\mathrm{MeOH}$ were used as a blank. The FRAP values are expressed as $\mathrm{mm} \mathrm{FeSO}_{4} / \mathrm{mg}$ dried plant (Griffin and Bhagooli, 2004).

\section{DPPH radical scavenging activity}

Serial dilutions of the test samples dissolved in $\mathrm{MeOH}$ were mixed with $\mathrm{DPPH}^{\bullet}(2 \mathrm{mg} / \mathrm{l})$ solution in 96-well microplates. $\mathrm{MeOH}$ was used as a negative control and (+)-catechin was used as a positive control. The change in absorbance at $517 \mathrm{~nm}$ was measured. Mean values were obtained from triplicate experiments. Inhibition percentage was calculated using the equation: \% inhibition $=[(\mathrm{A} 0-$ $\mathrm{A} 1) / \mathrm{A} 0] \times 100$, where $\mathrm{A} 0$ is the absorbance of the control and A1 the absorbance of the samples (Schmeda-Hirschmann et al., 2003). The radical scavenging activities were expressed as the median effective concentration $\left(\mathrm{EC}_{50}\right)$. The $\mathrm{EC}_{50}$ values were calculated from the log-dose inhibition curve obtained by a nonlinear regression algorithm (Prism, 4.0, GraphPad, GraphPad Software Inc., CA, USA).

\section{Isolation of active compounds}

The crude extract $(95 \mathrm{~g})$ was dissolved in dichloromethane $(\mathrm{DCM}, 4 \times 500 \mathrm{ml})$ to afford a DCM-soluble and a DCM-insoluble fraction. The DCM-insoluble portion of the extract $(29.21 \mathrm{~g})$ was resuspended in $\mathrm{DCM} / \mathrm{MeOH}(1: 1 \mathrm{v} / \mathrm{v})$ $(3 \times 500 \mathrm{ml})$ yielding a soluble and an insoluble fraction. The insoluble fraction $(13.67 \mathrm{~g})$ was dissolved in $\mathrm{MeOH} / \mathrm{H}_{2} \mathrm{O}(1: 1)$ and permeated on a Sephadex LH-20 column $(60.5 \times 5 \mathrm{~cm}$, flow rate $2 \mathrm{ml} / \mathrm{min}$ ) using $\mathrm{MeOH} / \mathrm{H}_{2} \mathrm{O}$ (1:1) to afford 107 fractions of $50 \mathrm{ml}$ each. The fractions were monitored by thin-layer chromatography on silica gel (EtOAc/acetic acid/formic acid/ $\mathrm{H}_{2} \mathrm{O} 100: 10: 10: 30$ $\mathrm{v} / \mathrm{v})$. After drying, the plates were sprayed with $0.5 \%$ diphenylboric acid in $\mathrm{MeOH}$ and the compounds visualized under UV light at 254 and $365 \mathrm{~nm}$. Fractions were pooled according to the TLC patterns into 5 fractions; fraction $\mathrm{B}(1.2 \mathrm{~g})$ was the most active DPPH scavenging fraction. Analytical DAD-HPLC of fraction B was carried out with a linear gradient of water $/ 1 \%$ formic acid (solvent A) and $\mathrm{MeOH}$ (solvent $\mathrm{B}$ ). The initial composition of the solvent system was $10 \% \mathrm{~B}$, $90 \% \mathrm{~A}$, changing to $20 \% \mathrm{~B}$ at $20 \mathrm{~min}$ and $75 \% \mathrm{~B}$ at $35 \mathrm{~min}$, returning to the initial conditions at 36 to $45 \mathrm{~min}$ with a flow rate of $1 \mathrm{ml} / \mathrm{min}$. For semipreparative HPLC, the running conditions were: $50 \% \mathrm{~A}, 50 \% \mathrm{~B}$ changing to $100 \% \mathrm{~B}$ at $45 \mathrm{~min}$, with 5 min of isocratic elution at $100 \%$ B before returning to the initial conditions at $65 \mathrm{~min}$ with a flow rate of $5 \mathrm{ml} / \mathrm{min}$.

\section{Results and Discussion}

The results of the preliminary phytochemical analysis revealed that the methanolic extract of $H$. drummondii shows a total phenolic and flavonoid content of $(32.36 \pm 0.86) \mathrm{mg}$ gallic acid eq/g extract and $(3.2 \pm 0.36) \mathrm{mg}$ catechin eq/g extract, respectively. The antioxidant properties of the extract were determined by the DPPH, ABTS and FRAP assays. The extract was capable of scavenging DPPH radicals in a concentration-dependent manner. The estimated median effective concentration $\left(\mathrm{EC}_{50}\right)$ was $(25.12 \pm 0.74) \mu \mathrm{g} / \mathrm{ml} .1 \mathrm{mg}$ of dry methanolic extract is equivalent to $(668 \pm$ 16.04) $\mu \mathrm{M}$ of Trolox, according to TEAC values in the ABTS $^{\bullet+}$ assay. The FRAP method measures the reducing capacity of the sample which is related to its antioxidant potential. The FRAP value for the extract was $(3.1 \pm 1.2) \mathrm{mm} \mathrm{FeSO}_{4} / \mathrm{mg}$ dry extract.

To isolate and identify the antioxidant compounds of $H$. drummondii, activity-guided fractionation of the methanolic extract was performed using the DPPH bleaching assay. Solvent partition of the crude $\mathrm{MeOH}$ extract with DCM afforded an inactive DCM-soluble fraction $\left(\mathrm{EC}_{50}>50 \mu \mathrm{g} /\right.$ $\mathrm{ml})$ and an insoluble part $\left[\mathrm{EC}_{50}(18.12 \pm 0.69) \mu \mathrm{g} /\right.$ $\mathrm{ml}$ ] which after partition with DCM/MeOH (1:1) yielded a DCM/MeOH extract $\left(\mathrm{EC}_{50}>20 \mu \mathrm{g} / \mathrm{ml}\right)$ and $13.67 \mathrm{~g}$ of insolubles [EC $50(11.32 \pm 0.54) \mu \mathrm{g} /$ $\mathrm{ml}$. From the DCM/MeOH (1:1)-insoluble fraction, after gel permeation, 5 combined fractions were obtained. While the $\mathrm{EC}_{50}$ values of fraction pools $\mathrm{A}, \mathrm{C}, \mathrm{D}$ and $\mathrm{E}$ were $>10 \mu \mathrm{g} / \mathrm{ml}$, fraction B showed an $\mathrm{EC}_{50}$ value of $(3.21 \pm 0.12) \mu \mathrm{g} / \mathrm{ml}$. From fraction pool B $(1.2 \mathrm{~g})$, after preparative HPLC, three main free radical scavenger compounds were isolated. The chemical structure of 
<smiles>O=C(O)/C=C/c1ccc(O)c(O)c1</smiles>

Caffeic acid (1)<smiles>[Y]C1C[C@](O)(C(=O)O)C[C@@H](O)[C@@H]1O</smiles>

$\mathrm{R}^{1} \quad \mathrm{R}^{2}$

affeoyl $\mathrm{OH}$

Chlorogenic acid Neochlorogenic acid (3)

H OCaffeoyl<smiles>O=C(O)c1ccc(O)cc1</smiles>

p-Hydroxybenzoic acid (5)<smiles>O=C(/C=C/c1ccc(O)c(O)c1)OC(=O)[C@H](Cc1ccc(O)c(O)c1)C(=O)O</smiles>

Rosmarinic acid (4)<smiles>[R1]Oc1cc(-c2cc(=O)c3c(O)c([R])c([R])c([R])c3o2)ccc1O</smiles>

Fig. 1. Structure of the compounds isolated from the aerial parts of $H$. drummondii.

caffeic acid (1) (133 mg), chlorogenic acid (2) $(213 \mathrm{mg})$, with traces of neochlorogenic acid (3), and rosmarinic acid (4) (219 mg) (Fig. 1) was elucidated on the basis of UV-Vis, ${ }^{1} \mathrm{H},{ }^{13} \mathrm{C}$ NMR, MS spectroscopic and spectrometric data as well as by comparison with reference samples (Kumaran and Karunakaran, 2007; Lu and Foo, 1999). The free radical scavenging activity of the compounds (as $\mathrm{EC}_{50}$ values in $\mu \mathrm{g} / \mathrm{ml}$ ) were $(1.78 \pm 0.2)$, $(3.53 \pm 0.14)$ and $(2.73 \pm 0.25)$ for caffeic acid, chlorogenic acid and rosmarinic acid, respectively. Under the same experimental conditions, the $\mathrm{EC}_{50}$ value of $(+)$-catechin was $(1.56 \pm 0.12) \mu \mathrm{g} / \mathrm{ml}$. The HPLC chromatogram of the active pool fraction $\mathrm{B}$ is presented in Fig. 2. From the less active fraction pool D, $41 \mathrm{mg}$ of sideritoflavone (6) precipitates in $\mathrm{MeOH}$ at $-10{ }^{\circ} \mathrm{C}, 92 \mathrm{mg}$ of luteolin-7-Oglucoside (7) and $56 \mathrm{mg}$ of $p$-hydroxybenzoic acid (5) were obtained and identified by comparison of the spectroscopic data with literature ones (Kuhnt et al., 1994; Lu and Foo, 1999). As far as we know, there are no references in the literature concerning the isolation of these phenolic acids as well as of the sideritoflavone derivatives from $\mathrm{H}$. drummondii; therefore this is the first report. GC-MS analysis of the DCM-soluble part allowed the identification of pulegone $(\mathrm{Rt}=19.23 \mathrm{~min})$ and

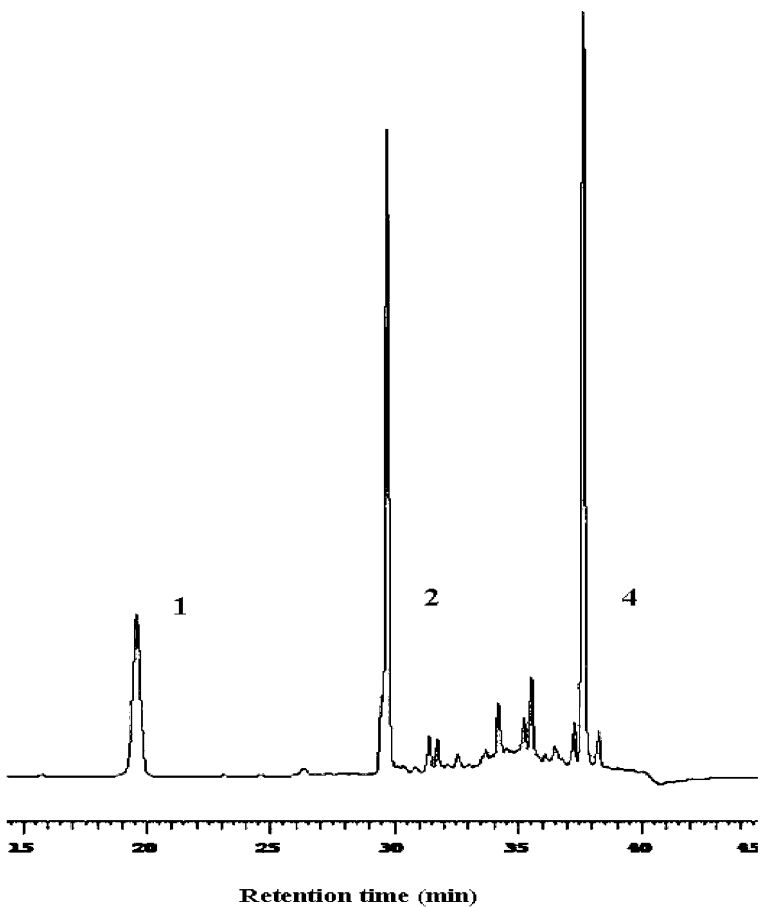

Fig. 2. HPLC trace of fraction pool B from H. drummondii aerial parts. 1, Caffeic acid; 2, chlorogenic acid; 4, rosmarinic acid. 
menthol $(\mathrm{Rt}=16.92 \mathrm{~min})$ as the major monoterpene constituents of the aromatic fraction.

From the methanolic extract of the aerial parts of $H$. drummondii, three main compounds were identified as the free radical scavengers/antioxidant constituents. Caffeic acid, chlorogenic acid and rosmarinic acid could be clearly associated with the activity of the extract. While caffeic acid showed a DPPH bleaching effect comparable to that of (+)-catechin, chlorogenic and rosmarinic acids were about half as active as the positive control.

The occurrence of sideritoflavone and rosmarinic acid in the Mexican plant Hyptis verticillata, used by the Mixe Indians, was reported by Kuhnt et al. (1994), while luteolin glycosides, including its 7-O- $\beta$-D-glucoside were identified in Salvia officinalis by Lu and Foo (1999). The variation of free phenolic acids in Lamiaceae plants was published by Zgórka and Głowniak (2001). The authors revised the phenolic acid content in Polish medicinal plants from the Lamiaceae family, and found that rosmarinic acid was the most predominant phenolic compound in the analyzed plant parts. Chlorogenic acid was found only in two samples, and the caffeic acid content was the highest in Ocimum

Andersen L. F., Jacobs Jr. D. R., Carlsen M. H., and Blomhoff R. (2006), Consumption of coffee is associated with reduced risk of death attributed to inflammatory and cardiovascular diseases in the Iowa Women's Health Study. Am. J. Clin. Nutr. 83, 1039-1046.

Chang C., Yang M., Wen H., and Chern J. (2002), Estimation of total flavonoid content in propolis by two complementary colorimetric methods. J. Food Drug Anal. 10, 178-182.

Dorman H. J. D., Peltoketo A., Hiltunen R., and Tikkanen M. J. (2003), Characterization of the antioxidants properties of de-odourised aqueous extracts from selected Lamiaceae herbs. Food Chem. 83, $255-262$

Estrada E., Villarreal J. A., Cantú C., Cabral I., Scout L., and Yen C. (2007), Ethnobotany in the Cumbres de Monterrey National Park, Nuevo León, Mexico. J. Ethnobiol. Ethnomed. 3, 8.

Gilmore M. R. (1913), Some native Nebraska plants with their uses by the Dakota. Nebraska State Historical Soc. Coll. 17, 358-370.

González F. M. (1998), Plantas medicinales del Noreste de Mexico. Editorial El Sol, Monterrey, Nuevo Leon, Mexico, p. 24.

Grayer R. J., Eckert M. R., Veitch N. C., Kite G. C., Marin P. D., Kokubun T., Simmonds M. S. J., and Paton basilicum. The presence of rosmarinic acid in $H$. drummondii is of interest as this compound has been shown to display immunomodulating, antiviral, antioxidant (Lima et al., 2007), anticarcinogenic and anti-inflammatory properties (Osakabe et al., 2004; Huang and Zheng, 2006). A review on rosmarinic acid was recently published by $\mathrm{Pe}$ tersen and Simmonds (2003).

Caffeic acid has been reported as a strong antioxidant (Lim et al., 2003) and chlorogenic acid and its isomers are long known for their free radical/ antioxidant effect (Niggeweg et al., 2004). Olthof et al. (2001) have shown that chlorogenic and caffeic acid are effectively absorbed in the intestinal tract and can be detected in blood.

\section{Acknowledgements}

Financial support from the Programa de Investigación en Productos Bioactivos (Universidad de Talca, Chile) is thankfully acknowledged. We thank Dr. Iván Razmilic, Universidad de Talca, Chile, for running the GC-MS spectra and the Proyecto MECESUP UCH 0116 from the Red Nacional de Doctorado en Química (Chile) for the mass spectra. Ezequiel Viveros-Valdez thanks IMSS and CONACYT (191633) for financial support.

A. J. (2003), The chemotaxonomic significance of two bioactive caffeic acid esters, nepetoidins $\mathrm{A}$ and $\mathrm{B}$, in the Lamiaceae. Phytochemistry 64, 519-528.

Griffin S. P. and Bhagooli R. (2004), Measuring antioxidant potential in corals using the FRAP assay. J. Exp. Mar. Biol. Ecol. 302, 201-211.

Heinonen M. I., Meyer A. S., and Frankel E. N. (1998), Antioxidant activity of berry phenolics on human lowdensity lipoprotein and liposome oxidation. J. Agric. Food Chem. 46, 4107-4112.

Huang S. S. and Zheng R. L. (2006), Rosmarinic acid inhibits angiogenesis and its mechanism of action in vitro. Cancer Lett. 239, 271-280.

Kuhnt M., Rimpler H., and Heinrich M. (1994), Lignans and other compounds from the Mixe indian medicinal plant Hyptis verticillata. Phytochemistry 36, 485-489.

Kumaran A. and Karunakaran R. J. (2007), Activityguided isolation and identification of free radicalscavenging components from an aqueous extract of Coleus aromaticus. Food Chem. 100, 356-361.

Lim E.-K., Higgins G. S., Li Y., and Bowles D. J. (2003), Regioselectivity of glucosylation of caffeic acid by a UDP-glucose:glucosyltransferase is maintained in planta. Biochem. J. 373, 987-992.

Lima C. F., Valentao C. R., Andrade P. B., Seabra R. M., Fernandes-Ferreira M., and Pereira-Wilson C. (2007), 
Water and methanolic extracts of Salvia officinalis protect HepG2 cells from t-BHP induced oxidative damage. Chem. Biol. Interact. 167, 107-115.

Lu Y. and Foo L. Y. (1999), Rosmarinic acid derivatives from Salvia officinalis. Phytochemistry 51, 91-94.

Luyten C. R., van Overveld F. J., De Backer L. A., Sadowska A. M., Rodrigus I. E., De Hert S. G., and De Backer W. A. (2005), Antioxidant defence during cardiopulmonary bypass surgery. Eur. J. Cardiothorac. Surg. 27, 611-616.

Ness A. R. and Powles J. W. (1997), Fruit and vegetables, and cardiovascular disease: a review. Int. J. Epidemiol. 26, $1-13$.

Neto C. C. (2007), Cranberry and blueberry: Evidence for protective effects against cancer and vascular diseases. Mol. Nutr. Food Res. 51, 652-664.

Niggeweg R., Michael A. J., and Martín C. (2004), Engineering plants with increased levels of the antioxidant chlorogenic acid. Nat. Biotechnol. 22, 746-754.

Olthof M. R., Hollman C. H., and Katan M. B. (2001), Chlorogenic acid and caffeic acid are absorbed in humans. J. Nutr. 131, 66-71.

Osakabe N., Yasuda A., Natsume M., and Yoshikawa T. (2004), Rosmarinic acid inhibits epidermal inflammatory responses: anticarcinogenic effect of Perilla frutescens extract in the murine two-stage skin model. Carcinogenesis 25, 549-557.

Petersen M. and Simmonds M. S. J. (2003), Rosmarinic acid. Phytochemistry 62, 121-125.

Proestos C., Sereli D., and Komaitis M. (2006), Determination of phenolic compounds in aromatic plants by RP-HPLC and GC-MS. Food Chem. 95, 44-52.

Re R., Pellegrini N., Proteggente A., Pannala A., Yang M., and Rice-Evans C. (1999), Antioxidant activity applying an improved ABTS radical cation discoloration assay. Free Radic. Biol. Med. 26, 1231-1237.

Record I. R., Dreosti I. E., and McInerney J. K. (2001), Changes in plasma antioxidant status following con- sumption of diets high or low in fruits and vegetables or following dietary supplementation with an antioxidant mixture. Brit. J. Nutr. 85, 4459-4464.

Rogers D. J. (1980), Lakota Names and Traditional Uses of Native Plants by Sicangu (Brule) People in the Rosebud Area, South Dakota. Rosebud Educational Society, St. Francis, SD, p. 49.

Schmeda-Hirschmann G., Rodríguez J. A., Theoduloz C., Astudillo L., Feresin G. E., and Tapia A. (2003), Free radical scavengers and antioxidants from Peumus boldus Mol. ("Boldo"). Free Radic. Res. 37, 447-452.

Singleton V. L. and Rossi Jr. J. A. (1965), Colorimetry of total phenolics with phosphomolybdic-phosphotungstic acid reagents. Am. J. Enol. Viticult. 16, 144-158.

Spiteller G. (2006), Peroxyl radicals: inductors of neurodegenerative and other inflammatory diseases. Their origin and how they transform cholesterol, phospholipids, plasmalogens, polyunsaturated fatty acids, sugars, and proteins into deleterious products. Free Radic. Biol. Med. 41, 362-387.

Steinmetz K. A. and Potter J. D. (1991), Vegetables, fruit and cancer. I. Epidemiology. Cancer Cause Control 2, 325-357.

Vestal P. A. (1952), The ethnobotany of the Ramah Navaho. Peabody Mus. Papers (Archaeol. Ethnol. Pap.) 40, 1-94.

Wang H., Cao G., and Prior R. L. (1996), Total antioxidant capacity of fruits. J. Agric. Food Chem. 44, 701-705.

Youdim K. A., McDonald J., Kalt W., and Joseph J. A. (2002), Potential role of dietary flavonoids in reducing microvascular endothelium vulnerability to oxidative and inflammatory insults. J. Nutr. Biochem. 13, 282288.

Zgórka G. and Głowniak K. (2001), Variation of free phenolic acids in medicinal plants belonging to the Lamiaceae family. J. Pharmaceut. Biomed. Anal. 26, $79-87$. 